\title{
An Anthropometric Approach to the Measurement of Poverty
}

Rodrigo Lopez-Pablos

Graduate Thesis

Department of Economics

Faculty of Economics Sciences

National University of La Plata

Director: Facundo Crosta

Coordinator: Ricardo Bebczuk

La Plata, June 2009 


\title{
An Anthropometric Approach to the Measurement of Poverty
}

\author{
Rodrigo Lopez-Pablos ${ }^{* \dagger}$
}

June 2, 2009

\section{Contents}

1 Introduction 1

2 Anthropometric Deprivation and Poverty 2

3 Anthropometric Deprivation and its Measurement 4

3.1 Anthropometric Deprivation: Significance and Classification. . . . 5

3.1.1 Classification of Malnutrition According to its Severity. . . 6

3.2 Reinterpretation of Anthropometric Poverty . . . . . . . . . . 7

4 Data and Basic Results $\quad 7$

4.1 By Constructing of the Alpha Variable . . . . . . . . . . . . 8

4.2 Scaling up the Standard Values . . . . . . . . . . . . . . . . . . . . 9

4.3 Equivalent Adult Income and Poverty Lines . . . . . . . . . . . . 10

5 Methodological Approximation $\quad 11$

5.1 Income and Anthropometric Head-Counts . . . . . . . . . . . . . 11

5.2 Poverty and Indigent Anthropometric Gaps . . . . . . . . . . . . 11

5.3 Two-dimensions Anthropometric F-G-T Indexes . . . . . . . . . . 12

5.3.1 Anthropometric Bidimensional Space . . . . . . . . . . . 12

5.3.2 Income-Anthropometry Bidimensional Space . . . . . . . . 12

5.4 Anthropometric Gini for Poor and Indigent Individuals . . . . . . 13

5.5 Anthropometric Sen Index . . . . . . . . . . . . . . . . . . 13

${ }^{*}$ The author acknowledges Ricardo Bebczuk and Facundo Crosta for their collaboration on the direction and coordination of this thesis, as well as Irene Brambilla, Mariana Marchionni, Natalia Porto and Martín Tetaz for their invaluable comments at the Thesis Seminar of the Department of Economics - UNLP.

†E-mail to: rodrigo. lopezpablos@educ.ar 
6 Empiric Results $\quad 14$

6.1 Unidimensional Analysis . . . . . . . . . . . . . . . . . . . 14

6.2 Bidimensional Analysis . . . . . . . . . . . . . . . . . . 15

$\begin{array}{lll}7 & \text { Conclusions } & 17\end{array}$

$\begin{array}{ll}\text { APPENDIX } & 21\end{array}$

$\begin{array}{lr}\text { A Figures } & 21\end{array}$

B Tables 22 


\begin{abstract}
From a multidimensional perspective on the analysis of poverty, an anthropometric dimension has been added as an integral reference of welfare, reinterpreting the physiological significance of the existence of different types of malnutrition among 0.5 to 6 year old children, as well as those children who will suffer a global deficiency in their essential capabilities and functionings in the future. Two-dimensional FGT, Sen and Gini anthropometric indexes have shown that malnourished families not only do have the most unequal income but also that the future poor people generation in the NEA and NOA regions will be the worst affected in terms of cultural and cognitive capacities.
\end{abstract}

Keywords: food crisis, anthropometric deprivation, malnutrition, anthropometric poverty, bidimensional F-G-T, anthropometric Sen index.

JEL Classification: D30, I32, I19

\title{
Resumen
}

Desde una perspectiva multidimensional al análisis de la pobreza, se adicionó una dimensión antropométrica como referencia integral de bienestar humano, reinterpretando el significado fisiológico de la existencia de diferentes tipos de desnutrición presente en niños Argentinos entre 0,5 y 6 años de edad como el de aquellos que sufrirán carencias globales sobre sus capacidades y funcionalidades esenciales en el futuro. Indices FGT bidimensional, Sen y Gini antropométricos demostraron que familias desnutridas no sólo poseen distribuciones del ingreso más desiguales, el NEA y NOA serán también las más perjudicadas en términos de capacidades cognitivas y culturales en la siguiente generación de pobres.

Palabras Clave: crisis alimentaria, deprivación antropométrica, desnutrición, pobreza multidimensional, FGT bidimensional, Sen antropométrico.

Clasificación JEL: D30, I32, I19 


\section{Introduction}

Infant mortality seems to be an unavoidable feature of the human race; currently, 6 million children under 5 die every year in the world as a direct or indirect cause of malnutrition (Basset and James-Levinson 2007, [1]); this undoubtedly shows one of the current, most asymmetric and cruelest facts of the human existence. In the international context of high prices of basic goods until mid-2008, the World Bank estimates noticed that the increase in food prices immediately led nine hundred million new poor people to poverty and one hundred million people to starvation (The World Bank News 2008, [20]); this meant the beginning of a world food crisis.

The future is so tragic that global-scale malnutrition specialists such as the Director of the United Nation World Food Program (WFP) Josette Sheeran calls the phenomenon a 'silent Tsunami' (U.N. News Centre 2008, [21]) which will devastate the poorest and lowest-income populations of the planet.

Sorrowfully, the phenomenon is not bounded to the poorest regions of Africa or Asia, in Latin America, in countries such as Haiti, families eat 'mud crackers', a mixture of mud, water, a bit of oil and salt (Pina K. 2008, [13]) to tackle starvation.

Taking into consideration the current food contexts, it is hoped that this work will help people become conscious of the need to have updated information about the social dimension of nutrition conditions, so relevant and sensitive when it comes time to fight long-term, firmly rooted, chronic poverty.

The fact that Argentina is one of the world's food producers leads to the idea that the food crisis would not affect the country deeply. However, it has been a fact since the 2001 crisis, particularly in the Northeast and Northwest regions; malnutrition among the poorest people is a latent cause which this work would like to explain in great detail.

To consider such phenomenon when measuring chronic poverty, it is necessary to add social dimensions which represent the nutrition conditions of all the individuals living in a particular area or place. Using income as the only evidence of welfare is therefore a limiting search to try to truthfully measure poverty levels from one generation to another.

In that search, and by means of a multidimensional poverty theory, an income variable and two anthropometric variables (weight-for-height and height-for-age) are evaluated, as measurements of nutrition development.

Empirically, the work core will be the study of multidimensional poverty in up-to-6-year- old children, by means of the incorporation of an anthropometric dimension to the measurement of poverty as a measurement of incapabilities and disfuctionings of the next generation by adding developing children's current nutrition conditions.

Additionally, one of the key objectives of this work is to enhance the scope to the future measurement of anthropometric deprivation, in moments when there 
is available updated anthropometric data of several periods, so as to be able to assess its evolution through panel data analysis.

At present is carried out:

(i) The identification of the poorest and lowest-income groups of the population, who are more sensitive to increases in food prices.

(ii) The study of the different degrees of anthropometric deprivation or malnutrition, among the low-income sub-groups of the population.

(iii) The study of the existence of links between income and anthropometric deprivation, as well as their distribution among those anthropometrically deprived, quantifying their impact through already existing poverty indexes.

(iv) A new understanding and interpretation of anthropometric poverty coefficients, in terms of future capability and functioning losses.

(v) The identification of areas of application of policies focused on fighting malnutrition in the new national and world food crisis context.

(vi) The identification of research lines in the poverty economics by using anthropometric variables to fight against the most urgent, firmly rooted poverty.

In the following section the theoretical poverty and malnutrition framework is presented; then the nature and measurement of the anthropometric deprivation is described in Chapter 3. The description of the data base is made in Chapter 4; Chapter 5 deals with the approximation to the measurement of anthropometric poverty. The hypotheses and empiric results obtained are detailed in Chapter 6. Finally, Chapter 7 presents the arrived conclusions arrived at and the current state of science in reference to the future research lines in the field of multidimensional poverty.

\section{Anthropometric Deprivation and Poverty}

Literature defines poverty as a multidimensional phenomenon. For this reason, it is necessary to determine all possible forms of poverty which societies may suffer from. Although the present work will not be a specific multidimensional approximation work -two-dimensional instead-, it will seek to add an anthropometric dimension to the study of poverty with the aim of re-directing the perception of what is considered poverty among the most affected strata in direct correlation with the most firmly rooted, persistent structural poverty within a group of people.

Due to the integral nature of the phenomenon, Amartya Sen (1985, 1992, 1999; [15][17][18]) rules out the concept of poverty as a mere scarcity of income. 
He suggests expanding the concept of poverty so that it also comprises all those people who are not able to develop basic capabilities and functionings to attain a level of initial welfare. Hence the question: How can a person develop all their capabilities without a biological support to make it possible? In that search, anthropometry comes up as one of the simplest and most secular ways used to measure such basic support in people's development.

In terms of equal opportunities, and leaving genetic differences aside, ensuring each individual's full mental and physical capabilities should be the obligation of any nation towards their citizens. Therefore, to guarantee equal opportunities in terms of nutrition, should also be a priority of any social science that advocates to the human welfare analysis. In this work, tools are proposed and developed to fully appreciate the magnitude and depth of the anthropometric deprivation on individuals within a certain group of people.

Anthropometry is extensively accepted as the most practically used tool to evaluate the nutrition status of human beings in general, and in particular, of children and adolescents in their stages of development. The individuals size as their anthropometric status, is also used as a measurement of life quality given the fact that they offer welfare measurement in relation to the natural development of individuals physical prop.

Among the wide range of literature that comprises different aspects of anthropometry, it is very necessary to mention Robert Fogel's (1986, 1987, 2004, 2004b; [4][5][6][7]) key contributions to economics and biometrics as he was the first to combine anthropometric, nutritional and bio-medic variables with a sharp understanding of health conditions and its consequences on welfare economics. Fogel, among other contributions, related the prevalence of chronic diseases, disabilities and infant mortality to anthropometric variables such as height and body mass index.

For this reason, even though the present work emphasizes the study of multidimensional poverty, it does have, from the very beginning, a Fogel spirit due to its inherent nature.

Other important contributions can be appreciated in Steckel (1995, [19]), who looks for links between incomes and the anthropometric measurement height as an alternative way of measuring life standards. Steckel himself widely revised the economics-anthropometric literature and found a positive correlation between height and levels of income per capita among individuals; he also found a high sensitivity in height variable among the lowest-income groups taking into consideration 16 countries with low and high average incomes in 1990 and 1991.

By addressing welfare multidimensionality, Sen (1985, 1992, 1999; [15][17][18]) suggested that besides observing income as a measurement of welfare and poverty, the individual's functionings and capabilities should also be observed; hence, a person's welfare should be defined as the presence of essential functionings to develop tasks, and the capabilities as the extent of a person's indispensable means to develop them. 
In this way, poverty indexes should be used to notice individuals' inability to attain a minimum level of basic capabilities in order to function and develop; it would also be possible to perceive individuals' inabilities to, for example, be healthy, well-nourished, educated, protected, etc.

To measure them, Bourguignon and Chakravarty $(2003,[2])$ proposed a quantitative theory that makes it possible to expand Foster, Greer and Thorbecke's (1984, [8]) poverty indexes into multiple dimensions, so as to reflect people's (functionings shortage in a more comprehensive way, and individuals' lack of material wealth, in a more representative way.

At local level, one of the few existent works that pretends to reflect the evolution of such lacks from a multidimensional measurement of poverty, Conconi and Ham (2007, [3]), offered an analysis of relative multidimensional poverty for Argentina using the Ongoing Household Survey (Encuesta Permanente de Hogares - EPH) between the 1998-2002 periods on different economy dimensions: labor condition, housing, education and income. They found an increasing tendency in social levels of exclusion as a result of the multidimensional measurement.

This work advances towards a multidimensional measurement of poverty taking into consideration the same theoretical structure developed by Bourguignon and Chakravarty (2003, [2]), but only using two dimensions of child's welfare: incomes and anthropometry. In this way the results shown here offer information about the current, as well as the long-term poverty study of the general welfare of the population represented.

\section{Anthropometric Deprivation and its Measure- ment}

Anthropometry, especially weight and size, constitutes the most direct, low cost, non-invasive, trustworthy, reproducible and objective way of measuring nutritional status due to its capacity to sum up the nutritional history of individuals, as well as of populations.

According to the World Health Organization (WHO 1986, [23]) anthropometric variables are used to create indicators of nutritional statuses. Among many evaluation methods, the use of the pediatric ' $z$-score' is preferred; it homogenizes the presentation, the analysis and the interpretation of anthropometric data for the nutritional evaluation of a population.

Three basic anthropometric variables: size, weight and age are combined to create the two fundamental anthropometric indexes weight-for-height $(\mathrm{W} / \mathrm{H})$ and height-for-age $(\mathrm{H} / \mathrm{A})$, which are widely used in the nutritional evaluation of a developing individual. They consider the standard individual deviation of every child with respect to the median of the population of reference as a means to qualify the growth of an individual into normal or malnourished. 
Due to the necessity of a reference population which exceeds the regional genetic differences, and in the search of standardization to measure malnutrition among 0-5 year old children including Argentina, the values used are those of the $\mathrm{W} / \mathrm{H}$ and $\mathrm{H} / \mathrm{A}$ average population made by Sociedad Argentina de Pedriatía (Argentine Pediatric Society) for the whole country. (Lejarraga 1987, [11]).

According to the WHO International Standards (1986, [23]), both evaluation indexes of nutritional development are obtained as follows:

$$
\mathrm{Z}_{i j}=\frac{x_{i j}-\text { med }_{i j}}{s d_{i j}}
$$

The number of individuals $i$ will be the number of toddlers $\mathrm{N}$ in the sample considered, so that $i=(1, \ldots, N)$ between the age range from 0 to 5 years, recommended by the WHO for the nutritional appreciation.

The $\mathrm{Z}$ score of the $i$ developing individual, according to the anthropometric variable $j=(1,2)$ will then be the result of the difference between its anthropometric value $x$ and med, the average of the population of reference corresponding to sex and age, in standard deviation units.

As $j$ may be $j=1,2$ whether the $\mathrm{W} / \mathrm{H}$ or $\mathrm{H} / \mathrm{A}$ variables are considered, there are averages of reference according to age and sex, which finally conform the two key variables for the characterization of the nutritional state upon which this work is based.

\subsection{Anthropometric Deprivation: Nutritional Significance and Classification.}

Anthropometric deprivation or child malnutrition can initially be classified into two basic categories: wasting and stunting.

The first mentioned, also called acute malnutrition or emaciation, can be attributed to a child's tissue or body mass deficit in comparison with other children of the same height, and are identified with the reported variable values weight-forheight which are lower than two standard deviations with respect to the average of reference. One of the characteristics of wasting is that it can appear and disappear quickly according to the environment. That is why seasonal phenomena such as diet variation, illnesses or food provision may condition it.

The second category, stunting or chronic malnutrition, is synonymous with a decrease of the speed of skeletal growth and it is identified with the reported values of the variable height-for-age which are lower than two standard deviations. On the other hand, this nutritional status has been associated with conditions of general poverty in multiple dimensions of welfare (housing, education, income, etc.) for a long time. This type of anthropometric deprivation is undoubtedly the most worrisome due to the fact that the irreversible damage it causes to toddlers today will bring about after-effects for the rest of their lives. 


\subsubsection{Classification of Malnutrition According to its Severity.}

Additionally, Waterlow's classification et. al. (1977, [22]), is taken into consideration; it orders what has been stated above according to its severity, and it also takes into account those cases in which both phenomena appear together (stunting) and (wasting), differentiating the shortened individual's malnutrition between mild and severe. In this classification, the mild-chronic malnutrition is also called compensated because it presents a normal speed of growth; by contrast, the severe-chronic malnutrition is called decompensated because it is related to an abnormal speed of growth.

To graphically summarize the above mentioned information and incorporating threshold values according to the Standards of the World Health Organization Bulletin (WHO 1976, [23]) the following chart represents the toddler's classification in accordance with the standard ' $\mathrm{Z}$ score' compiled for the $\mathrm{W} / \mathrm{H}$ and $\mathrm{H} / \mathrm{A}$ values - from now onwards referred to as $z_{i 1}$ and/or $z_{i 2}$ respectively - between 6-month to 5-year-old children who suffer from some kind of nutritional lack as can be appreciated below.

Table 1: Malnutrition Classification According to Type.

\begin{tabular}{|c|c|c|}
\hline $\mathrm{T} / \mathrm{E}-\mathrm{P} / \mathrm{T}$ & $Z_{i 1}>-2 s d$ & $Z_{i 1}<-2 s d$ \\
\hline$Z_{i 2}>-2 s d$ & Normal & $\begin{array}{c}\text { Wasted } \\
\text { Acute Malnutrition }\end{array}$ \\
\hline$Z_{i 2}<-2 s d$ & $\begin{array}{c}\text { Stunted } \\
\text { Chronic Malnutrition } \\
\text { (Mild) }\end{array}$ & $\begin{array}{c}\text { Stunted \& Wasted } \\
\text { Chronic Malnutrition } \\
\text { (Severe) }\end{array}$ \\
\hline
\end{tabular}


On the basis of this anthropometric classification, given the nutritional welfare, the making up of a nutritional status variable will be backed up in the subsequent measurement of poverty severity, indigence and anthropometric deprivation.

\subsection{Reinterpretation of Anthropometric Poverty}

When it comes time to evaluate children in their full physical and cognitive development stages, a specific interpretation is presented in relation to these individuals' future functionings, where it is possible to have a feeling of what proportion of the population may have problems in terms of general functionings and capabilities when they reach their adulthood.

In reference to Sen's vision, which has already been described above, (capabilities and functionings), a special interpretation is made when handling the analysis of the anthropometric dimensionality meaning; which makes it possible to measure the welfare of the child's biological support by considering the irreversible nature of malnutrition and its consequences at an early age: an unappropriated nourishment support is the origin of all future multidimensional deprivations, in terms of the development of human capabilities and functionings (see Ortale 2003, [12]), which the current anthropometrically deprived will suffer at their mature age. ${ }^{1}$

This interpretation, generational indeed, and even based on recent crosssectional data; tries in fact to find representative coefficients of those who will present irretrievable shortages once their biological stage of development in the early years of life has ended.

\section{Data and Basic Results}

The National Health and Nutrition Survey (Encuesta Nacional de Salud y Nutrición - ENNyS) carried out by the National Ministry of Health gathers economic, demographic, biochemical and anthropometric characteristics of Argentina, collected during the second semester 2004 and first semester 2005. It contains national and regional representative cross-sectional data with very detailed information about household socio-economic characteristics, and several measures for children, whereby is the source of the income and anthropometric variables here considered.

${ }^{1}$ From the discussions arisen at the Thesis Seminar where the reason of the empiric evaluation on children was questioned, -Irene Bambrilla's contribution- it has been agreed that besides the vision and interpretation of the use of anthropometric variables as an additional welfare measurement, lacks of nutrition are also directly associated with the probability of infant death. 
In the survey, it is possible to identify 12.435 observations of 0.5 to 6 year old children of both sexes, provided for every representative region of the country.

Due to the fact that 536 children observations were of families whose heads of households informed have done some jobs but without declaring any kind of income, the incomes for that sub-group were estimated by means of Heckman's censured model, in two stages (Heckman 1979, [10]); as an estimate of a non declared head of household income as can be seen in the Appendix, Table 3. In the Appendix, Table 3 only corresponds to the second part of the estimation of salaries; in it, traditional regressors to Mincer's estimations such as education, attendance, age, squared age - as proxy variable to labor experience - and the number of family members were used, all of which turned out to be significant.

By means of this regression, the 536 observations were replaced by the estimate values obtained, as the supposed incomes (salaries) of those heads of households who did not state any salary although they were working.

In the Appendix, Table 4, as an analogy to income dimensions, the Ongoing Household Survey (Encuesta Permanente de Hogares - EPH) per person was considered together; the data corresponds to the period of the ENNyS making for the whole country and only takes into consideration boys and girls who were up to six years old by the time the survey was carried out, in order to evaluate the consistency and parallelism between the surveys. There, it is possible to appreciate the number of toddlers considered for every region, as well as the different levels of average income in each survey.

In the same Appendix, Table 4, have been calculated the average values of the two fundamental anthropometric variables: weight-for-height $\left(z_{i 1}\right)$ and height-forage, $\left(z_{i 2}\right)$ trying to look for significant regional differences. As can be appreciated, standard anthropometric values do not differ significantly from one region to the other with respect to the median of reference of the Argentine Pediatric Society (Sociedad Argentina de Pediatría - SAP). ${ }^{2}$ When observing the standard deviation with respect to the value median in both indexes, it is clear that in neither case was reported a variable which exceeds the critical thresholds of the two standard deviations with reference to the average coefficients obtained.

\subsection{By Constructing of the Alpha Variable}

Starting from the malnutrition classification according to the severity evaluated in the two basic anthropometric variables: weight-for-height $\left(z_{i 1}\right)$ and heightfor-age $\left(z_{i 2}\right)$, a variable of the state of anthropometric deprivation was created according to the degree of malnutrition level reported by the toddler and which will be called alpha $(\alpha)$, as shown in Table 2 .

\footnotetext{
${ }^{2}$ Due to the fact that the SAP presents a table of reference for the whole country, it is be possible to make a deeper analysis about the implications that the existence of genetic differences might have among the different regions - Mariana Marchionni and Martín Tetaz's comments-.
} 
Table 2: An order for the severity of malnutrition according to type

\begin{tabular}{|c|c|c|}
\hline $\mathrm{T} / \mathrm{E}-\mathrm{P} / \mathrm{T}$ & $Z_{i 1}>-2 s d$ & $Z_{i 1}<-2 s d$ \\
\hline$Z_{i 2}>-2 s d$ & $\begin{array}{c}\text { Normal } \\
\left(\boldsymbol{\alpha}\left(\mathbf{z}_{\mathbf{i} \mathbf{j}}\right)=0\right)\end{array}$ & $\begin{array}{c}\text { Wasted } \\
\text { Acute Malnutrition } \\
\left(\boldsymbol{\alpha}\left(\mathbf{z}_{\mathbf{i 1}}\right)=2\right)\end{array}$ \\
\hline$Z_{i 2}<-2 s d$ & $\begin{array}{c}\text { Stunted } \\
\text { Chronic Malnutrition } \\
(\text { Mild }) \\
\left(\boldsymbol{\alpha}\left(\mathbf{z}_{\mathbf{i} 2}\right)=3\right)\end{array}$ & $\begin{array}{c}\text { Stunted \& Wasted } \\
\text { Chronic Malnutrition } \\
\text { (Severe) } \\
\left(\boldsymbol{\alpha}\left(\mathbf{z}_{\mathbf{i j}}\right)=4\right)\end{array}$ \\
\hline
\end{tabular}

In this way, and by means of this new variable of order according to the degree of severity of the anthropometric deprivation obtained, an undernourished individual is identified as one who belongs to a family which reports at least one undernourished or emaciated member, regardless of the type of their specific malnutrition. Used as an initial counter, the alpha variable will adopt a $\left(\alpha\left(z_{i j}\right)^{+}=1\right)$ value to measure the total proportion of all kinds of undernourished individuals ${ }^{3}$.

Nevertheless, the alpha variable per se will only consider values between 2 and 4 according to every type of child anthropometric deprivation. These values increase in a monotonous way; the depth of child malnutrition levels increase: the alpha variable becomes a $2\left(\alpha\left(z_{i 1}\right)\right)$ value in the cases of wasting; a $3\left(\alpha\left(z_{i 2}\right)\right)$ value when malnutrition is mild chronic or the child is stunted in relation to age, and a $4\left(\alpha\left(z_{i j}\right)^{*}=4\right)$ value in the most extreme cases, when children not only do show stunting but also wasting, a phenomenon known as acute chronic malnutrition. This simple variable of order plays a fundamental role in the subsequent analysis of two-dimensional indicators.

\subsection{Scaling up the Standard Values}

Due to the fact that the variables weight-for-height $\left(z_{i 1}\right)$ and height-for-age $\left(z_{i 1}\right)$ belong to the real negative and positive values, this is: $\left(z_{i 1}, z_{i 2}\right) \in \mathbb{R}$.

If the anthropometric values were not scaled to the real positive values, this would bring about serious problems when applying methods of aggregation, since we have to take advantage of the existing analytic structure of indicators which have been made on the basis of positive income assumptions.

Due to the fact that the standard anthropometric variables naturally tend to

\footnotetext{
${ }^{3}$ Notice that $\alpha\left(z_{i j}\right)^{+}=1$ can also be understood as the total sum between acute undernourished and mild chronic undernourished individuals $\alpha\left(z_{i j}\right)=1=\alpha\left(z_{i 1}\right)+\alpha\left(z_{i 2}\right)$.
} 
a normal distribution with median equal to zero, the standard variables $z_{i j}$ were scaled adding up the minimum value observed ${ }^{4}$ so that:

$$
Z_{p / t}+\min \left(\bar{z}_{i 1}\right) Z_{t / a}+\min \left(\bar{z}_{i 2}\right) \Rightarrow\left(Z_{p / t}^{\prime}, Z_{t / a}^{\prime}\right) \in \mathbb{R}^{+}
$$

Rescaling the standard values to the first positive quadrant of real numbers, it is possible to maintain the properties of the depth and severity poverty indexes subsequently considered.

\subsection{Equivalent Adult Income and Poverty Lines}

Since the information about the age of all members of every family surveyed by the ENNyS is not available, it was impossible to calculate the adult equivalent measures for individuals below 6 years old. Therefore, the equivalent income was calculated for every income decile by using the EPH periods parallel to the ENNyS, which did have the ages of all the individuals surveyed accordingly to each region.

The poverty lines of the adult equivalent income to be considered will be the lines average stated by the National Department of Census and Statistics (Instituto Nacional de Estadística y Censo - INDEC), corresponding to the period the survey was carried out, at current prices, as can be seen in the following table:

Table 5: Indigence and poverty lines 2004-2005

\begin{tabular}{lcccccc}
\hline Income Lines & GBA & Cuyo & NEA & NOA & Pampeana & Patagonia \\
\hline $\mathrm{p}_{1}$ (Poor $)$ & 244.46 & 213.25 & 216.55 & 211.33 & 221.15 & 232.13 \\
$\mathrm{p}_{2}$ (Indigents $)$ & 111.17 & 99.27 & 99.83 & 97.83 & 104.94 & 115.06 \\
\hline
\end{tabular}

Source: Author's estimation based on the officials poverty lines 2004-2005.

These represent the official poverty and extreme poverty lines corresponding to 2004-2005 periods when the ENNyS was carried out.

\footnotetext{
${ }^{4}$ Facundo Crosta's contribution as a technique to scale up values to the first quadrant.
} 


\section{Methodological Approximation to the Anthro- pometric Poverty Measurement}

To fully appreciate anthropometric poverty, is proceeded to adopt the already existing poverty measurements by adding an anthropometric dimension to their estimations.

First, the incidence rate is calculated by means of head-counts for every poor, indigent, and any child presenting whatever kind of malnutrition. Then, the poverty, indigent and anthropometric gaps are calculated to later advance towards the study of income distribution of the anthropometric poor through a conditional Gini index in child nutritional states.

Once the above mentioned components are obtained, it will not be difficult to calculate the income and anthropometry Sen Indexes for every type. Finally, the two-dimensional FGT indexes of generational severity in the transmission of chronic poverty are estimated.

\subsection{Income and Anthropometric Head-Counts}

Prevalence rates or head-counts for every region, for poor and indigent children are calculated as follows:

$$
H_{y_{p}}=\frac{1}{N} \sum_{i=1}^{N} I\left(y_{i} \leq \bar{y}_{p}\right)
$$

Additionally, four head-counts are calculated, one for each type of reported malnutrition, or in other words, one for every "alpha" state, so that:

$$
H_{\alpha\left(z_{i j}\right)}=\frac{1}{N} \sum_{i=1}^{N} I\left(z_{i j} \leq \bar{z}_{i j}\right)
$$

Four anthropometric head-counts are obtained for all and every type of special anthropometric deprivation.

\subsection{Poverty and Indigent Anthropometric Gaps}

In the same way it has been proceeded with the head-counts, at first by calculating the income gaps for poor and indigent individuals as follows:

$$
P_{y_{p}}=\frac{1}{N} \sum_{i=1}^{N}\left(1-\frac{y}{\bar{y}_{p}}\right) I\left(y \leq \bar{y}_{p}\right)
$$

At the same time the anthropometric gaps are calculated as follows: 


$$
P_{\alpha\left(z_{i j}\right)}=\frac{1}{N} \sum_{i=1}^{N}\left(1-\frac{z_{i j}}{\bar{z}_{i j}}\right) I\left(z_{i j} \leq \bar{z}_{i j}\right)
$$

Four anthropometric gaps will be obtained for all and every type of special anthropometric deprivation.

\subsection{Two-dimensions Anthropometric F-G-T Indexes}

Taking into consideration Foster, Greer and Thorbecke (1984, [8]) index but converting the alpha term into a variable according to Chapter 2, two types of two-dimensional indexes appear: one in the income-anthropometry space and the other in the anthropometry-anthropometry space; both spaces will have at least one anthropometric dimension represented by the degree of malnutrition severity $\left(\alpha\left(z_{i j}\right)\right)^{5}$. Not only do these indexes have the capacity to grasp income severity but they can also appreciate the degree of child malnutrition severity in relation to their height and age.

\subsubsection{Anthropometric Bidimensional Space}

In the $\left(z_{i j}, \alpha\left(z_{i 1}, z_{i 2}\right)\right) \in \mathbb{R}^{+}$space, to every anthropometric variable $\left(z_{i 1}, z_{i 2}\right)$ a bidimensional FGT will be added according to the alpha variable severity of the nutritional state reported by the toddler, as can be seen in the following:

$$
F G T\left(z_{i j}, \alpha\left(z_{i j}\right)\right)=\frac{1}{N} \sum_{i=1}^{N}\left(1-\frac{z_{i j}}{\bar{z}_{i j}}\right)^{\alpha\left(z_{i j}\right)} I\left(z_{i j} \leq \bar{z}_{i j}\right) ; \alpha\left(z_{i j}\right) \geq 0
$$

\subsubsection{Income-Anthropometry Bidimensional Space}

In the same way, but this time about the income-anthropometry space:

$\left(y_{i j}, \alpha\left(z_{i 1}, z_{i 2}\right)\right) \in \mathbb{R}^{+}$, the variable of the severity degree of the anthropometric deprivation, $\alpha\left(z_{i j}\right)$, punishes exponentially the lower distance of the minimum threshold of those children who belong to families which have adult equivalent incomes under the poverty or indigent line, so that:

$$
F G T\left(y_{p}, \alpha\left(z_{i j}\right)\right)=\frac{1}{N} \sum_{i=1}^{N}\left(1-\frac{y_{i}}{\bar{y}}\right)^{\alpha\left(z_{i j}\right)} I\left(y_{i} \leq \bar{y}_{l p}\right) ; \alpha_{z} \geq 0
$$

Both will be very useful in the event they are applied to children in their full process of developing, as a measurement of future deficiencies in terms of Sen's functionings -functionings, (see Sen 1985, 1992 and 1999; [15][17][18])-.

\footnotetext{
5 Alternatively, this indicator of two-dimensional severity can be considered a special case of the multidimensional index developed by Bourguignon and Chakravarty (2003, [2]).
} 


\subsection{Anthropometric Gini for Poor and Indigent Individuals}

Additionally, the intention of this work has been that of evaluating the income distribution of those individuals presenting nutritional deprivation. In order to do this, the Gini indexes were calculated for every type of poor individual, according to the poverty line, indigence and anthropometric thresholds.

Following is the Gini index of adult equivalent incomes for every child presenting some type of malnutrition:

$$
G_{y, \alpha\left(z_{i j}\right)}=\frac{1}{2 q^{2} m_{p}} \sum_{k=1}^{q} \sum_{l=1}^{d}\left|y_{k}-y_{l}\right| \quad \forall \quad \alpha\left(z_{i j}\right)>0 \quad j=1,2 \quad i=1 \ldots N
$$

From this, four anthropometric Gini indexes of income will be obtained for all and every type of special anthropometric deprivation.

\subsection{Anthropometric Sen Index}

Once the head-counts, the poverty gaps and the Ginis for every type of poorindigent child are obtained, it is not difficult to calculate the Sen Indexes for every type of poor-indigent child, according to income, anthropometry or both conjointly.

According to the Sen Index (1976, [14]) of income, the following:

$$
\operatorname{Sen}_{y_{p}}=H\left(1-\left(1-G_{y_{p}}\right) \frac{\mu_{y_{p}}}{z}\right)
$$

It can be restated as:

$$
\operatorname{Sen}_{y_{p}}=H_{y_{p}} G_{y_{p}}+P_{y_{p}}\left(1-G_{y_{p}}\right)
$$

The above mentioned provides the two Sen Indexes of income for poor and indigent children. However, the following information will provide indexes for every type of anthropometric deprivation:

$$
\operatorname{Sen}_{y, \alpha\left(z_{i j}\right)}=H_{\alpha\left(z_{i j}\right)} G_{y_{i}, \alpha\left(z_{i j}\right)}+P_{\alpha\left(z_{i j}\right)}\left(1-G_{y_{i}, \alpha\left(z_{i j}\right)}\right)
$$

From this, four anthropometric Sen Indexes of income will be obtained for all and every type of special anthropometric deprivation. 


\section{Empiric Results}

Among the most important hypothesis that there will try to respond by means of the empiric results obtained, we have the following:

(i) What type of anthropometric poverty or malnutrition affects every region most predominantly?

(ii) How is income distributed in those families with individuals under 6 who presented some type of malnutrition?

(iii) Is there a relationship between human deprivation in terms of income and anthropometry?

(iv) What regions present the most severe types of malnutrition with the highest implications on long-term generational poverty?

\subsection{Unidimensional Analysis}

By tackling the one-dimensional empiric analysis, can be seen in the Table 6 of the Appendix the results obtained in terms of poverty prevalence, indigence and every type of deprivation or anthropometric poverty according to the degree of malnutrition evaluated.

As can be seen in Table 6, NEA and NOA regions, not only do they lead the percentage of poor and indigent children in reference to incomes ${ }^{6}$, but they also lead, on a national level the highest indexes of prevalence in reference to every type of anthropometric poverty $\left(H_{(1)}\right)$.

The NOA region reported the highest values of severe and mild-chronic malnutrition or stunting $\left(H_{(3)}\right)$. It is remarkable that the Patagonia region revealed the highest levels -followed by the NEA region- of the worst type of anthropometric poverty: chronic-severe malnutrition or simultaneous stunting and wasting $\left(H_{(4)}\right)$.

In Table 7 can be observed the measurements of poverty and indigent gaps in terms of income $\left(P_{y_{p 1}}, P_{y_{p 2}}\right)$, as well as the anthropometric gaps as a measurement of the distance between severe malnutrition values reported under their respective threshold, considering that: $z_{i 1}<-2.0\left(P_{(2)}\right)$ o $z_{i 2}<-2.0\left(P_{(3)}\right)$.

Due to the fact that there are only two anthropometric variables $\left(z_{i 1}, z_{i 2}\right)$ to calculate anthropometric gaps of every pure type of malnutrition, and none to calculate their combinations $\left(P_{(1)}, P_{(4)}\right)^{7}$, the anthropometric gaps for severe undernourished individuals, or general malnutrition regardless of its type $\left(P_{(1)}\right)$, are calculated from the multiplication or addition of $P_{(2)}$ y $P_{(3)}$, whichever applies.

\footnotetext{
${ }^{6}$ As a way of comparing, the coefficients obtained were included, using the EPH periods corresponding to the analog period of the ENNyS making - 2004-2005.

${ }^{7}$ See section 4.1 .
} 
In terms of income, the NEA region leads poverty and extreme poverty gaps, followed by the NOA region. The Pampa region showed the highest chronic mild malnutrition gaps $\left(P_{(3)}\right)$, as well as the highest general anthropometric gap. On the other hand, Cuyo region showed the highest levels of wasted children $\left(P_{(2)}\right)$ and severe undernourished children $\left(P_{(4)}\right)$.

In the Appendix, Table 8 the degree of poverty severity or conventional FGT index can be appreciated, assuming a constant alpha variable $(\bar{\alpha}=2)$ regardless the child's nutritional state.

\subsection{Bidimensional Analysis}

Following, the bidimensional FGT indexes are described according to the (6) and (7) equations, as can be observed in Table 9 of the Appendix. The NEA and NOA regions are the most affected in the bidimensional anthropometry-income space; this tells us that in these regions the lack of purchasing power is dangerously combined with the lack of skills necessary to break free from the vicious circle of poverty, and at the same time, it assures a prevalence of range and generational transmission in terms of incapabilities and inabilities in these regions.

According to the types of malnutrition in the bidimensional anthropometryanthropometry spaces, we have found a higher severity of acute malnutrition in Cuyo, Patagonia and NOA regions, whereas GBA and Pampa regions presented higher values of chronic malnutrition severity. Such findings could be used to the design of nutrition policies for every type of malnutrition, for every region according to their severity.

On the basis of this criterion, in Cuyo, Patagonia and NOA regions, resources and efficient nutrition policies to ensure a basic biological support for their populations should be prepared to cope with recoverable or compensable malnutrition in the short or long term. This is different in the NEA or GBA regions, where policies should be structured and implemented in the long term, especially to break the generational transmission of structural poverty.

Evaluating the distribution of adult equivalent incomes in poor, indigent or anthropometric poor families using the Gini index (??) (8), the Table 10 of the Appendix presents the values obtained for.

As can be observed in Table 10, the Pampa and NEA regions have the core of poor and indigent children, with the most unequal income $\left(G_{y_{p_{1}}}, G_{y_{p_{2}}}\right)$. On the other hand, regardless the region or type of anthropometric deprivation $\left(G_{y, 1}\right)$, undernourished children belong to families who have adult equivalent incomes worse distributed than those who are only under the official poverty and extreme poverty lines, without taking into account their nutrition state. In this case, the NOA and NEA regions present the most unequal income among their undernourished population $\left(G_{y, 1}, G_{y, 3}\right.$ y $\left.G_{y, 4}\right)$.

As a graphic view of distribution, it is possible to appreciate Lorenz's general distributions among poor, indigent and undernourished individuals in every 
Argentine region ${ }^{8}$ at the Appendix's Figures subsection.

In Figure 1, it is now possible to visually appreciate a worse situation in terms of inequality for those anthropometric poor individuals in the Pampa, NEA and NOA regions. Among the indigent children, the Pampa and the NEA regions reflected the highest income inequality. In Figure 3, Lorenz's curves of income can be appreciated; they are more curved and concentrated among those children who have any type of anthropometric lack. NOA and NEA regions are the ones which have the most unequal incomes among families who suffer anthropometric deprivation.

Starting from the Gini index, incidence rates and poverty gaps, according to the (11) equation, are calculated the Sen indexes as can be seen in Table 11 of Appendix.

According to Table 11, the conventional Sen Indexes reflect a worse situation in the distribution and prevalence of income in the NEA and NOA regions among poor $\left(S_{y_{p_{1}}}\right)$ as well as indigent $\left(S_{y_{p_{2}}}\right)$ children. Additionally, and as it was expected, first the NOA and then the NEA regions reported the highest anthropometric Sen Indexes in all types of malnutrition $\left(S_{(1)}\right)$; severe malnutrition $\left(S_{(2)}\right)$ and mild chronic malnutrition $\left(S_{(3)}\right)$, with the exception of severe chronic malnutrition $\left(S_{(4)}\right)$ leaded by Cuyo and NEA regions. To sum up, it is evident that the North of Argentina is the most affected part of the country in terms of anthropometric poverty, and as a consequence the most in need region in terms of long term nutrition and cultural policies.

\footnotetext{
${ }^{8}$ Graphics represent the expansion corresponding to the Gini index of anthropometric poor individuals $G_{y, 1}$.
} 


\section{Conclusions}

The aim of this document is to shed light on this issue from the economy of welfare and multidimensional poverty, towards the search of additional tools to indentify and focus on the prevailing generational and chronic poverty within a social group.

The linkage line pursued comprises the study of human nutrition by means of anthropometric variables and multidimensional poverty indexes. The transdisciplinary work contents have enabled us to reach a new interpretation of chronic poverty states as those which will affect future poor adults' functionings and capabilities.

Although the measurements of anthropometric poverty could be very useful for places with higher levels and depths of anthropometric deprivation, such as Indian and African regions, in Argentina, and especially in the north, child malnutrition is a reality, as well as it is and will be a threat for the cognitive and physiological development of the children of today, but conditioning their capabilities and functionings of the adults of tomorrow.

In the unidimensional analysis, the rates of income incidence, with some exceptions in the specific consideration of malnutrition states according to type, seem to have an awaited relationship with anthropometric deprivation, as shown for the NOA and NEA regions. However, the story was not the same for the gap coefficients of income and anthropometry; in this case Cuyo and Pampa regions exceeded the NEA and NOA regions.

In the bidimensional analysis, the FGT presented a higher depth of anthropometric poverty in the NEA and NOA regions, which will suffer a higher chronic poverty among poor members of the following generation. The same indicator but only about the anthropometry space presents a higher depth of extreme poverty in the Cuyo region, whereas the GBA region is the most affected in terms of chronic poverty. The latter with significant implications in future terms of functional and biological underdevelopment.

It was established that those anthropometric poor individuals presented more unequal incomes than those who were poor and indigent according to their incomes. In terms of Gini and Sen anthropometric distribution, the NOA region, in particular, showed higher income inequalities among undernourished families than all the other regions.

Considering future possible research lines, in the case of counting on anthropometric economics panel data ${ }^{9}$, it would be possible to enhance the evaluation spectrum of the evolution of anthropometric poverty, on concepts such as growth rate, for an analysis of a more precise evolution of nutritional states; it would even be possible to use treatment and impact models to explain in great detail

\footnotetext{
${ }^{9}$ Natalia Porto mentioned the possibility of exploring the efficiency of other alternative anthropometric measurements also included in the survey.
} 
the efficiency of general health plans about the state of child development within a population or policies to improve the culture of nutrition of a population.

A natural extension of this work, in the same trans-disciplinary pattern, could be the incorporation of dimensions to the multidimensional spectrum, so as to truthfully reflect a global phenomenon such as children's poverty.

In the case of having panel data, another way could be a decomposition analysis of the bidimensional FGT indexes, which could be fruitful when it comes time to look for relationships between the different family characteristics and the different states of a detailed multidimensional poverty analysis.

Hoping to have promoted the spread of a new, national, broad-spectrum surveys such as the ENNyS, which in future editions would make the panel and evolution poverty analysis possible; the addition of new dimensionalities will help to better identify and understand such a broad phenomenon as children's poverty.

In addition to the investigation of deep children's poverty, this work has tried to take the first step towards the design of effective nutritional, educational and cultural policies in the long term against the most rooted and deepest poverty of an impoverished society. 


\section{References}

[1] Basset L. and James-Levinson F. (2007). "Malnutrition is still a major contributor to child deaths." Population Reference Bureau, Washington D. C.

[2] Bourguignon F. Chakravarty S. R. (2003). "The Measurement of Multidimensional Poverty." Journal of Economic Inequality. Springer vol. 1(1), pp. $25-49$.

[3] Conconi A. y Ham A. (2007). "Pobreza multidimensional relativa: una aplicación a la Argentina." CEDLAS, Documento de Trabajo 57. La Plata.

[4] Fogel, R. W. (1986). "Nutrition and the decline in mortality since 1700: Some pre-liminary findings," in Stanley L. Engerman and Robert E. Gallman (eds.), Long-Term Factors in American Economic Growth. University of Chicago Press, pp. 439-555. Chicago.

[5] Fogel, R. W. (1987). "Biomedical approaches to the estimation and interpretation of secular trends in equity, morbidity, mortality, and labor productivity in Europe, 1750-1980, Typescript." Center for Population Economics. University of Chicago. Chicago.

[6] Fogel, R. W. (2004). "Change in the disparities in chronic disease during the course of the twentieth century." NBER . Working Paper 10311. Cambridge.

[7] Fogel R. W. (2004b). "The Escape from Hunger and Premature Death, 17002100: Europe, America, and the Third World." Cambridge University Press. Cambridge.

[8] Foster J., J. Greer and E. Thorbecke A.K. (1984). "A class of descomposable poverty measure." Econometrica, 52, 761-765.

[9] Gini C. (1912). Variabilitá e mutabilitá. Bologna.

[10] Heckman, James. (1979). "Sample selection bias as a specification error." Econometrica 47, 153-161.

[11] Lejarraga H. et. al. (1987). "Crecimiento y desarrollo normas de diagnóstico y tratamiento." Sociedad Argentina de Pediatría. Buenos Aires.

[12] Ortale, M.S. (2003). "Pobreza y alimentación familiar. Reflexiones en base a estudios locales." 51 Congreso Internacional de Americanistas. Santiago de Chile.

[13] Pina, Kevin. (2008). "Mud cookie economics in Haití." Haiti Action Network, Feb. 10 Haití. 
[14] Sen, Amartya (1976). "Poverty: an ordinal approach to measurement." Econometrica 44 (2), 219-231.

[15] (1985). "Commodities and capabilities." North-Holland, Amsterdam.

[16] (1987). "The standard of living." Cambridge University Press, Cambridge.

[17] _ (1992). "Inequality reexamined." Hardvard University Press, Cambridge.

[18] (1999). "Development as freedom." Oxford University Press, Oxford.

[19] Steckel, Richard H. (1995). "Stature and the standard of living". Journal of Economic Literature 33 (December): 1903-40.

[20] The World Bank News (2008). "Food price crisis imperils 100 million in poor countries." April 14. http://web.worldbank.org/

[21] U.N. News Centre (2008). "Global food crisis 'silent tsunami' threathening over 100 million people, warns UN". tue, April 22. http://www.un.org/

[22] Waterlow, J. C. et. al. (1977). "The presentation and use of height and weight data for comparing the nutritional status of groups of children under the age of 10 years." Bulletin of the World Health Organization. 55: 489-498.

[23] WHO Working Group (1986). "Use and interpretation of anthropometric indicators of nutricional status." Bulletin of the World Health Organization, 64 (6) 929-941. 


\section{APPENDIX}

\section{A Figures}

Figure 1 Income Distribution - Poor Curva Generalizada de Lorenz - Pobres
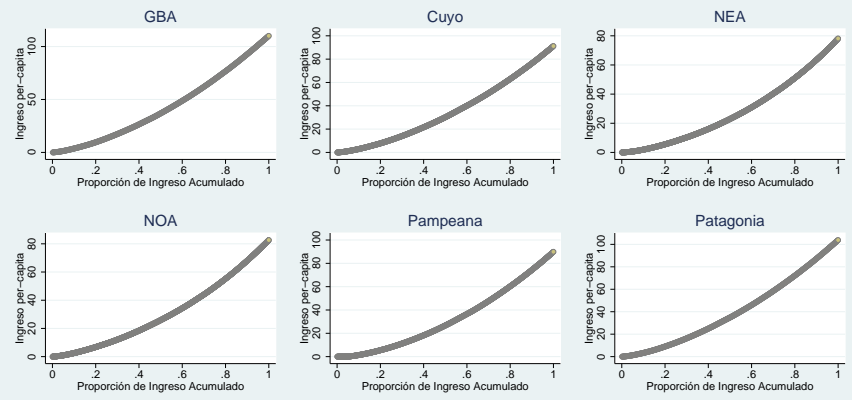

Source: Nutritional and Health National Survey (ENNyS) - 2005 .

Figure 2 Income Distribution - Indigents

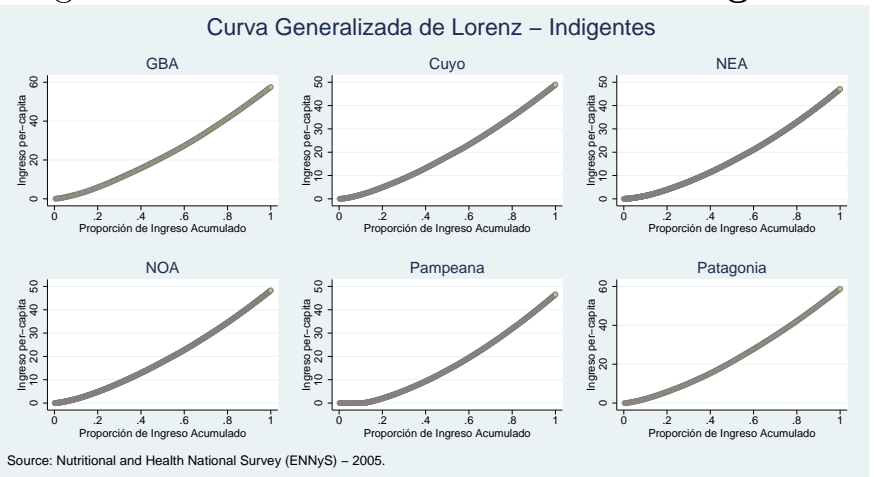

Figure 3 Income Distribution - Malnourished Curva Generalizada de Lorenz - Pobres Antropométricos
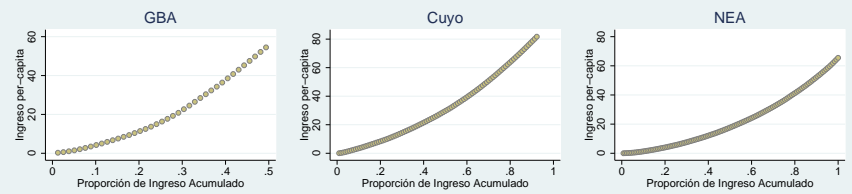

NOA

Pampeana
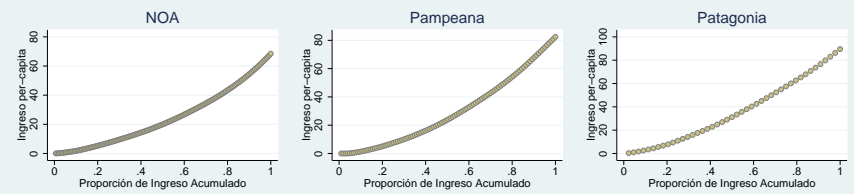

Source: Nutritional and Health National Survey (ENNyS) - 2005. 


\section{B Tables}

Table 3: Heckman's censured estimation (ln wage) (second step only)

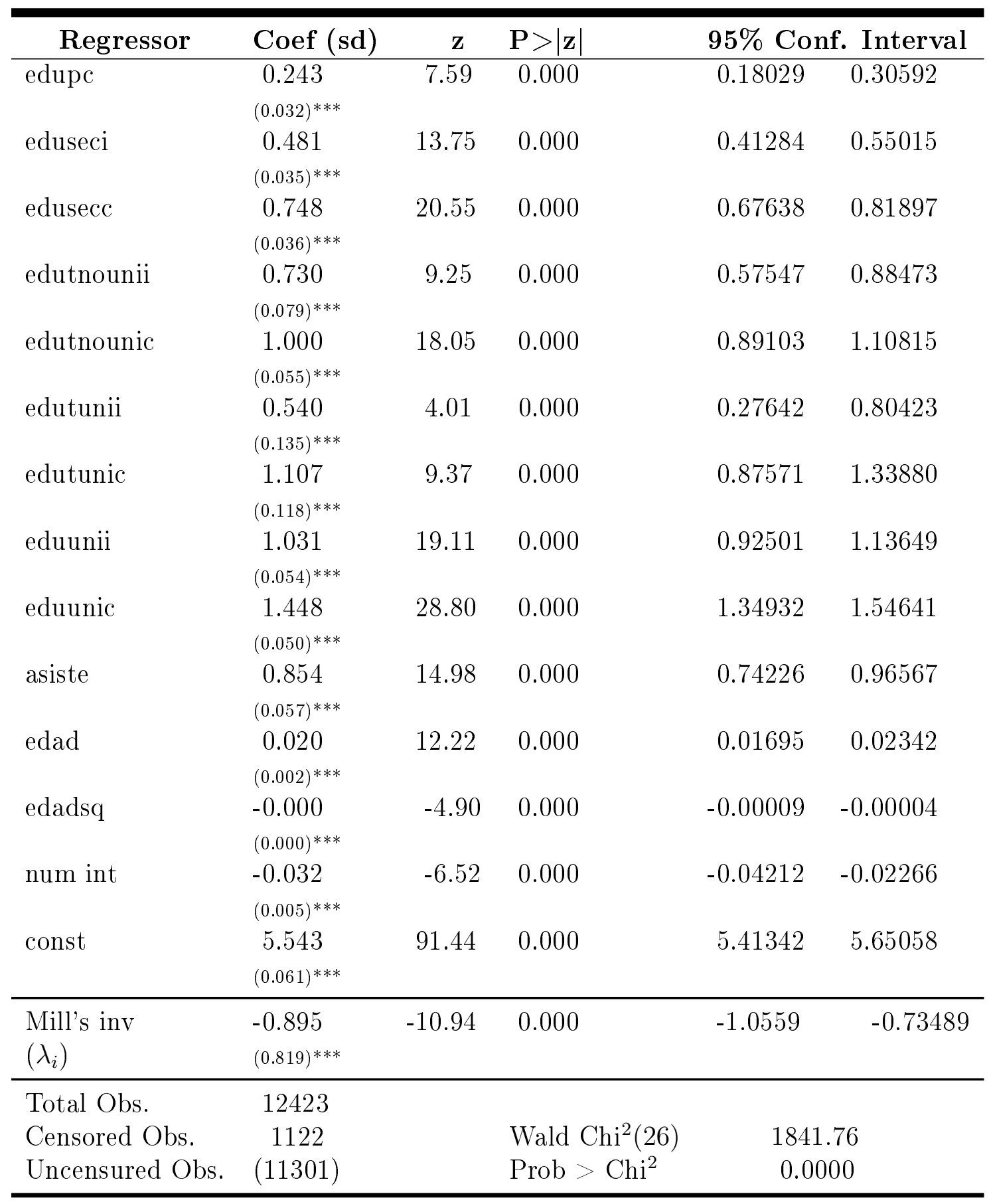

Source: Author's estimation based on ENNyS - 2004-2005.

$* * *$ significative at $1 \%$. ** significative at $5 \%$. ${ }^{*}$ significative at $10 \%$. 
Table 4: Children up to 6 years of age. (EPH \& ENNyS - 2004-2005)

\begin{tabular}{|c|c|c|c|c|c|c|c|}
\hline & GBA & Cuyo & NEA & $\mathrm{NOA}$ & Pampeana & Patagonia & Arg. \\
\hline \multicolumn{8}{|l|}{$\mathrm{EPH}$} \\
\hline Girls & 1156 & 696 & 833 & 1554 & 1821 & 469 & 6529 \\
\hline Boys & 1137 & 744 & 901 & 1544 & 1840 & 499 & 6665 \\
\hline Total & 2293 & 1440 & 1734 & 3098 & 3661 & 968 & 13194 \\
\hline Mean Income (MI) & 352.59 & 312.16 & 194.96 & 240.89 & 336.67 & 530.75 & 330.49 \\
\hline \multicolumn{8}{|l|}{ ENNyS } \\
\hline Girls & 748 & 1003 & 1043 & 1193 & 1229 & 910 & 6126 \\
\hline Boys & 796 & 1061 & 1114 & 1205 & 1165 & 968 & 6309 \\
\hline Total & 1544 & 2064 & 2157 & 2398 & 2394 & 1878 & 12435 \\
\hline Mean Income (MI) & 347.17 & 265.58 & 200.78 & 206.08 & 313.68 & 379.60 & 315.23 \\
\hline \multirow[t]{2}{*}{ Weight-Height $\left(\bar{Z}_{1 j}\right)$} & 0.584 & 0.292 & 0.137 & 0.295 & 0.526 & 0.511 & 0.472 \\
\hline & $(1.403)$ & $(1.335)$ & $(1.188)$ & $(1.239)$ & $(1.299)$ & $(1.259)$ & $(1.331)$ \\
\hline \multirow[t]{2}{*}{ Height-Age $\left(\bar{Z}_{2 j}\right)$} & -0.220 & -0.162 & -0.353 & -0.345 & -0.249 & -0.239 & -0.260 \\
\hline & $(1.180)$ & $(1.191)$ & $(1.169)$ & $(1.151)$ & $(1.206)$ & $(1.163)$ & $(1.180)$ \\
\hline
\end{tabular}

Source: Author's estimation based on ENNyS (2004-2005) and EPH (2004-2005) surveys.

Table 5: Indigence and poverty lines 2004-2005

\begin{tabular}{lcccccc}
\hline Income Lines & GBA & Cuyo & NEA & NOA & Pampeana & Patagonia \\
\hline $\mathrm{p}_{1}($ Poor $)$ & 244.46 & 213.25 & 216.55 & 211.33 & 221.15 & 232.13 \\
$\mathrm{p}_{2}$ (Indigents $)$ & 111.17 & 99.27 & 99.83 & 97.83 & 104.94 & 115.06 \\
\hline
\end{tabular}

Source: Author's estimation based on the officials poverty lines 2004-2005. 
Table 6: Head Counts

\begin{tabular}{lcccccccc}
\hline Region & $H_{y_{p_{1}}}$ & $H_{y_{p_{2}}}$ & $H_{1}$ & $H_{2}$ & $H_{3}$ & $H_{4}$ & $H_{y_{p_{1}}}^{E P H}$ & $H_{y_{p_{2}}}^{E P H}$ \\
\hline GBA & 48.72 & 15.66 & 4.941 & 0.84 & 4.23 & 0.130 & 54.10 & 23.53 \\
Cuyo & 54.43 & 17.69 & 7.312 & 2.24 & 5.12 & 0.049 & 49.53 & 19.06 \\
NEA & 69.77 & 36.68 & 7.601 & 1.48 & 6.26 & 0.139 & 70.58 & 36.24 \\
NOA & 69.12 & 31.47 & 8.517 & 1.70 & 6.90 & 0.083 & 63.21 & 30.04 \\
Pampeana & 47.26 & 20.01 & 7.218 & 1.11 & 6.15 & 0.042 & 48.28 & 20.92 \\
Patagonia & 42.23 & 15.77 & 6.190 & 0.82 & 5.53 & 0.160 & 30.72 & 14.04 \\
Argentina & 50.79 & 20.23 & 6.628 & 1.23 & 5.49 & 0.092 & 53.96 & 23.90 \\
\hline
\end{tabular}

Source: Author's estimation based on ENNyS (2004-2005) and EPH (2004-2005) surveys.

Table 7: Poverty, indigence, acute and chronic malnutrition gaps

\begin{tabular}{lrrrrrrrr}
\hline Region & $P_{\left(y_{p_{1}}\right)}$ & $P_{\left(y_{p_{2}}\right)}$ & $P_{(1)} \dagger$ & $P_{(2)}$ & $P_{(3)}$ & $P_{(4)} \ddagger$ & $P_{y_{p_{1}}}^{E P H}$ & $P_{y_{p_{2}}}^{E P H}$ \\
\hline GBA & 20.43 & 5.23 & 0.58 & 0.11 & 0.47 & 0.05 & 25.26 & 8.86 \\
Cuyo & 23.65 & 6.49 & 0.64 & 0.26 & 0.38 & 0.10 & 22.34 & 7.15 \\
NEA & 36.71 & 14.23 & 0.66 & 0.16 & 0.50 & 0.08 & 36.34 & 13.81 \\
NOA & 34.25 & 11.43 & 0.64 & 0.21 & 0.43 & 0.09 & 31.43 & 11.32 \\
Pampeana & 22.62 & 9.77 & 0.71 & 0.15 & 0.56 & 0.08 & 22.42 & 7.84 \\
Patagonia & 17.82 & 5.15 & 0.56 & 0.13 & 0.43 & 0.06 & 14.20 & 5.34 \\
Argentina & 23.27 & 7.67 & 0.64 & 0.15 & 0.49 & 0.07 & 25.51 & 9.00 \\
\hline
\end{tabular}

$\dagger: P_{(1)}=P_{(2)}+P_{(3)}$

$\ddagger: P_{(4)}=P_{(2)} * P_{(3)}$

Source: Author's estimation based on ENNyS (2004-2005) and EPH (2004-2005) surveys. 
Table 8: Conventional F-G-T: Poverty, indigence and malnutrition severity index $(\bar{\alpha}=2)$

\begin{tabular}{lcccccc}
\hline Region & $F G T\left(y_{p_{1}}, \bar{\alpha}\right)$ & $F G T\left(y_{p_{2}}, \bar{\alpha}\right)$ & $F G T\left(z_{i 1}, \bar{\alpha}\right)$ & $F G T\left(z_{i 2}, \bar{\alpha}\right)$ & $F G T\left(y_{p_{1}}^{E P H}, \bar{\alpha}\right)$ & $F G T\left(y_{p_{2}}^{E P H}, \bar{\alpha}\right)$ \\
\hline GBA & 11.31 & 2.52 & 0.04 & 0.14 & 15.32 & 4.60 \\
Cuyo & 13.18 & 3.15 & 0.06 & 0.05 & 13.13 & 3.76 \\
NEA & 23.28 & 7.59 & 0.03 & 0.08 & 23.00 & 7.27 \\
NOA & 20.64 & 5.54 & 0.08 & 0.05 & 19.38 & 5.94 \\
Pampeana & 14.61 & 6.84 & 0.04 & 0.13 & 13.41 & 4.17 \\
Patagonia & 9.77 & 2.47 & 0.05 & 0.08 & 8.50 & 2.93 \\
Argentina & 13.77 & 4.18 & 0.04 & 0.12 & 15.49 & 4.71 \\
\hline
\end{tabular}

Source: Author's estimation based on ENNyS (2004-2005) and EPH (2004-2005) surveys.

Table 9: Poverty, indigence and malnutrition generational deprivation Bidimensional F-G-T $\left(\alpha\left(z_{i j}\right)\right)$

\begin{tabular}{lcccc}
\hline Region & $F G T\left(y_{p_{1}}, \alpha\left(z_{i j}\right)\right)$ & $F G T\left(y_{p_{2}}, \alpha\left(z_{i j}\right)\right)$ & $F G T\left(z_{i 1}, \alpha\left(z_{i j}\right)\right)$ & $F G T\left(z_{i 2}, \alpha\left(z_{i j}\right)\right)$ \\
\hline GBA & 46.31 & 14.45 & 0.03 & 0.07 \\
Cuyo & 50.36 & 16.09 & 0.06 & 0.01 \\
NEA & 65.67 & 33.50 & 0.02 & 0.02 \\
NOA & 64.02 & 27.48 & 0.08 & 0.01 \\
Pampeana & 43.72 & 18.55 & 0.03 & 0.05 \\
Patagonia & 39.81 & 14.77 & 0.05 & 0.02 \\
Argentina & 47.38 & 18.34 & 0.04 & 0.05 \\
\hline
\end{tabular}

Source: Author's estimation based on the ENNyS survey (2004-2005). 
Table 10: Gini of the poor, indigents and malnourished

\begin{tabular}{lcccccc}
\hline Region & $G_{y_{p_{1}}}$ & $G_{y_{p_{2}}}$ & $G_{y, 1}$ & $G_{y, 2}$ & $G_{y, 3}$ & $G_{y, 4}$ \\
\hline GBA & 0.2348 & 0.1889 & 0.4380 & 0.4418 & 0.4017 & 0.0479 \\
Cuyo & 0.2348 & 0.1856 & 0.4125 & 0.3898 & 0.4237 & 0.0000 \\
NEA & 0.2882 & 0.2213 & 0.4564 & 0.4343 & 0.4441 & 0.1764 \\
NOA & 0.2618 & 0.1866 & 0.4737 & 0.4362 & 0.4797 & 0.4724 \\
Pampeana & 0.3113 & 0.3558 & 0.4352 & 0.3755 & 0.4406 & 0.0000 \\
Patagonia & 0.2296 & 0.1884 & 0.3821 & 0.3573 & 0.3759 & 0.1114 \\
Argentina & 0.2675 & 0.2297 & 0.4733 & 0.4488 & 0.4623 & 0.3333 \\
\hline
\end{tabular}

Source: Author's estimation based on the ENNyS survey (2004-2005).

Table 11: Sen index of the poor, indigents and malnourished

\begin{tabular}{lcccccc}
\hline Region & $S_{y_{p_{1}}}$ & $S_{y_{p_{2}}}$ & $S_{(1)}$ & $S_{(2)}$ & $S_{(3)}$ & $S_{(4)}$ \\
\hline GBA & 27.073 & 7.2005 & 2.4900 & 0.4325 & 1.9805 & 0.0554 \\
Cuyo & 30.877 & 8.5684 & 3.3919 & 1.0317 & 2.3882 & 0.0988 \\
NEA & 46.237 & 19.1983 & 3.8281 & 0.7333 & 3.0582 & 0.0904 \\
NOA & 43.379 & 15.1697 & 4.3715 & 0.8599 & 3.5339 & 0.0870 \\
Pampeana & 30.291 & 13.4132 & 3.5427 & 0.5105 & 3.0231 & 0.0840 \\
Patagonia & 23.425 & 7.1503 & 2.7114 & 0.3765 & 2.3472 & 0.0675 \\
Argentina & 30.632 & 10.556 & 3.4741 & 0.6023 & 2.8017 & 0.0796 \\
\hline
\end{tabular}

Source: Author's estimation based on the ENNyS survey (2004-2005). 